\title{
Histiocitose Cutânea Não-Langerhans Como Causa de Diabetes Insípido Central
}

\section{apresentação de caso}

\author{
Paulo A.C. Miranda \\ SILVANA M.C. MIRANDA \\ FLÁVIA V. BITTENCOURT \\ LUCAS J.C. MACHADO \\ LUCIA P.F. DE CASTRO \\ VIRGINIA H.R. LEITE \\ MÁrCIO W. LAURIA \\ WALTER R.C. BRAGA \\ ANTÔNIO RIBEIRO de OLIVEIRA JR.
}

Departamento de Clínica Médica (PACM, SMCM, FVB,

LJCM, MWL, WRCB \& AROJr) $e$ Departamento de Anatomia Patológica e Medicina Legal (LPFC \& VHRL), Faculdade de Medicina, Universidade Federal de Minas Gerais, Belo Horizonte,

MG.

Recebido em 04/10/06 Revisado em 19/01/07 Aceito em 23/03/07

\section{RESUMO}

As histiocitoses são doenças raras, resultantes de alterações na linhagem monocítica-histiocítica, com manifestações clínicas diversas. Entre as síndromes cutâneas de células não-Langerhans, o xantoma disseminado é a única entidade desse grupo classicamente associada ao diabetes insípido central (DIC). O caso clínico relatado refere-se a um paciente de 30 anos de idade que, dois anos após o diagnóstico de DIC, evoluiu com lesões cutâneas papulosas, eritêmato-acastanhadas, difusas, discretas e não confluentes. Os achados histológicos, imuno-histoquímicos e a microscopia eletrônica mostraram resultados compatíveis com a histiocitose de células não-Langerhans e sugestivos do xantogranuloma juvenil. A avaliação endócrino-metabólica não mostrou alterações durante o seguimento por 10 anos, com exceção do DIC. A ressonância magnética da hipófise demonstrou ausência do sinal hiperintenso (mancha brilhante) correspondente à neuro-hipófise. As radiografias e a cintilografia dos ossos não mostraram lesões osteolíticas. Este caso desperta a atenção para a importância do exame da pele nos casos de DIC e de sua associação com a histiocitose de células não-Langerhans de maneira mais ampla, e não restrita aos casos de xantoma disseminado. (Arq Bras Endocrinol Metab 2007;51/6:1018-1022)

Descritores: Xantomatose; Diabetes insípido; Histiocitose; Células de Langerhans; Xantogranuloma juvenil

\section{ABSTRACT}

Cutaneous Non-Langerhans Cells Histiocytoses as Cause of Central Diabetes Inspidus.

The histiocytoses are rare diseases caused by alterations in the monocytehistiocytic series with several clinical findings. Among the cutaneous syndromes of non-Langerhans cells, xanthoma disseminatum is the only disease of this group that has been classically associated to the central diabetes insipidus (CDI). The case reported describes a 30 -year-old man that two years after presenting with $\mathrm{CDI}$ developed non confluent disseminated cutaneous brown papular lesions throughout the body. The histopathology, immunohistochemistry, and electronic microscopy were compatible with the diagnosis of non-Langerhans histiocytoses, suggesting the diagnosis of juvenile xanthogranuloma. The endocrine-metabolic evaluation did not show other alterations besides CDI in a 10 -year follow up. The magnetic resonance of hypophysis showed absence of the pituitary hyperintense sign (bright spot). The radiologic and scinthigraphic evaluation of the bones did not show the presence of osteolytic lesions. This case prints out the importance of skin examination in cases of CDI and its association with cutaneous non-Langerhans histiocytoses in a broader spectrum, rather then restricted to the cases of xanthoma disseminatum. (Arq Bras Endocrinol Metab 2007;51/6:1018-1022)

Keywords: Xanthomatosis; Diabetes insipidus; Histiocytoses; Langerhans cells; Xanthogranuloma juvenile 
$\mathrm{O}$ DIABETES INSÍPIDO É UMA síndrome poliúrica decorrente de dois mecanismos principais: deficiência parcial ou total na síntese da vasopressina ou diminuição da sensibilidade renal a esse hormônio. Com base nesta fisiopatologia ele é classificado, respectivamente, como diabetes insípido central (DIC) total ou parcial e diabetes insípido nefrogênico (1).

Entre as múltiplas causas de DIC, destacam-se as histiocitoses, que representam um grupo extenso e heterogêneo de desordens decorrentes de alterações na linhagem celular dos monócitos/macrófagos. São geralmente classificadas em histiocitose de células de Langerhans e histiocitose de células não-Langerhans, de acordo com as características morfológicas e os marcadores fenotípicos das células envolvidas (2).

As histiocitoses de células de Langerhans resultam da proliferação de células histiocitárias tipo Langerhans que expressam positividade para a proteína S-100 e ao antígeno CDla e contêm os grânulos intracitoplasmáticos de Birbeck. Apresentam um espectro amplo de manifestações clínicas, desde quadros cutâneos localizados a formas sistêmicas graves, freqüentemente fatais. Embora compreenda classicamente três entidades (doença de Letterer-Siwe, doença de Hand-SchüllerChristian e granuloma eosinofílico), o conceito atual é que se trata de uma doença espectral com variação apenas quanto à extensão do envolvimento orgânico e prognóstico. Entre essas variantes de histiocitose de células de Langerhans, destaca-se a doença de Hand-SchüllerChristian, que se caracteriza pela tríade de diabetes insípido, exoftalmia e lesões ósseas destrutivas (3).

As histiocitoses de células não-Langerhans constituem um grupo de desordens caracterizadas pela proliferação benigna de histiócitos que não preenchem o fenótipo para o diagnóstico de células de Langerhans (S100 e CDla positivos, além dos grânulos de Birbeck). Trata-se de um grupo heterogêneo de doenças caracterizadas por lesões cutâneas polimorfas histioxantomatosas, podendo ocorrer ou não o acometimento sistêmico (4). Entre as diversas variantes de histiociose não-Langerhans, destaca-se o xantoma disseminado, entidade que em cerca de $40 \%$ dos casos associa-se ao diabetes insípido (5). No entanto, existem casos descritos na literatura que sugerem, assim como no presente relato, a associação do DIC com outros tipos de histiocitoses de células não-Langerhans (6).

Esta descrição de caso clínico tem como objetivo suscitar discussão relativa à associação do diabetes insípido a lesões de pele xantomatosas discretas e não características de xantoma disseminado, avaliando-se, assim, a hipótese de que a histiocitose de células não-Langerhans possa estar relacionada de forma mais ampla ao DIC.

\section{RELATO DO CASO}

Paciente de 30 anos, sexo masculino, leucoderma, com história de diabetes insípido há 12 anos, controlado com doses baixas de desmopressina (DDAVP). Há 10 anos apresenta lesões cutâneas papulosas, eritêmatoacastanhadas, medindo até $5 \mathrm{~mm}$, distribuídas aleatoriamente pelo corpo, com leve predomínio, entretanto, na sua porção superior (figura 1). Essas evoluíram com resolução espontânea sem deixar cicatrizes, exibindo caráter recorrente, sem acometimento mucoso.

A prova de restrição hídrica confirmou o diagnóstico de DIC, com resposta parcial ao DDAVP. A avaliação laboratorial dos demais hormônios do eixo hipotálamo-hipofisário por dosagens basais, em um seguimento de 10 anos, não evidenciou alterações, incluindo a ausência de hiperprolactinemia. O hemograma, glicemia, perfil lipídico, função hepática e renal encontravam-se dentro dos limites da normalidade. $\mathrm{O}$ exame oftalmológico foi normal.

A avaliação radiológica dos ossos longos não evidenciou a presença de lesões osteolíticas. A cintilografia óssea de corpo inteiro mostrou apenas a presença de lesão sugestiva de processo inflamatório em seios paranasais, o que foi posteriormente confirmado por imagem correspondente a pansinusite em tomografia computadorizada dos seios da face. A ressonância nuclear magnética (RNM) da hipófise evidenciou ausência do sinal hiperintenso, em Tl, correspondente à neuro-hipófise (mancha brilhante) e ausência de espessamento da haste hipofisária.

O exame histopatológico das lesões cutâneas pela hematoxilina-eosina ( $\mathrm{HE}$ ) (figura 2A) evidenciou derme com coleção de macrófagos xantomizados, al-

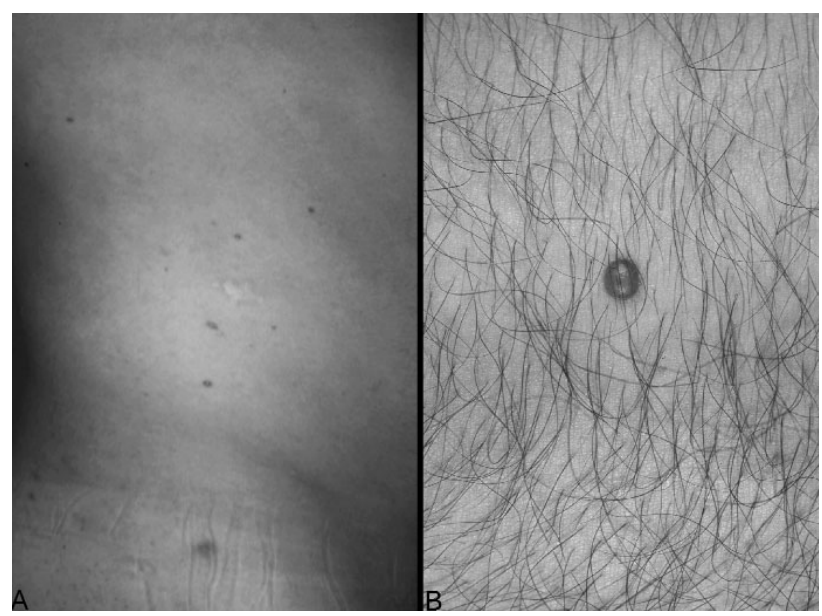

Figura 1. Lesão cutânea xantomatosa. (A) Lesões múltiplas em região tóraco-abdominal direita. (B) Em imagem aumentada, lesão papulosa, eritêmato-acastanhada. 
gumas células de Touton e a presença de células inflamatórias mononucleares compatíveis com o quadro de xantoma e sugestivas de xantogranuloma juvenil. A microscopia eletrônica confirmou histiocitose de células não-Langerhans, devido à ausência dos grânulos de Birbeck (figura 2B).

O exame imuno-histoquímico de uma das lesões (figura 3 ) revelou negatividade para o antígeno CDla, positividade para CD45, CD68, HLA-DR, e positividade fraca e irregular para a proteína $S-100$, o que favoreceu o diagnóstico de histiocitose não-Langerhans e sugeriu o xantogranuloma juvenil, forma adulta e múltipla, quando analisado conjuntamente com a história clínica e os achados morfológicos.

\section{DISCUSSÃo}

O caso relatado mostra o DIC como manifestação de uma doença xantomatosa. Essa associação nos remete à importância do exame detalhado da pele de pacientes portadores de diabetes insípido, uma vez que diversas formas dessa enfermidade consideradas idiopáticas podem ter como causa a infiltração hipotalâmica-hipofisária relacionada às lesões discretas da pele.

O DIC parcial neste paciente poliúrico foi confirmado pela prova de restrição hídrica e reforçado pela ausência da mancha brilhante hipofisária à RNM da hipófise. O brilho da hipófise posterior pode ser observado em 60 a 90\% dos pacientes hígidos em exames de rotina. Entretanto, sua ausência em exame dire-

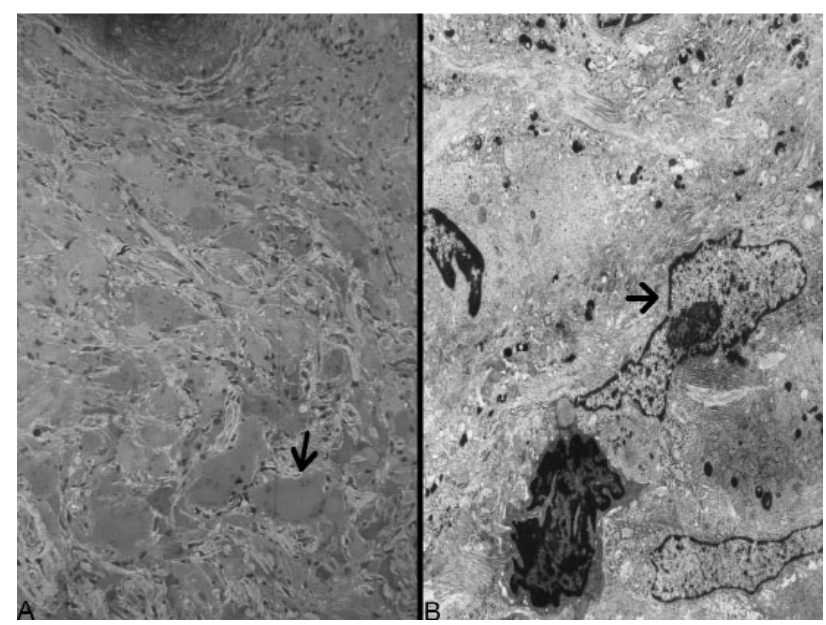

Figura 2. (A) Exame histopatológico mostrando células de Touton (seta), macrófagos xantomizados e infiltrado mononuclear. (B) Microscopia eletrônica evidenciando célula histiocitária; em destaque, o núcleo com nucléolo evidente (seta), com ausência de grânulos de Birbeck em seu citoplasma cionado, de boa resolução espacial, deve ser considerada patológica até que se prove o contrário (7). Outras alterações, como o espessamento da haste hipofisária e a presença de massa supra-selar, não foram evidenciadas, $\mathrm{O}$ que seria muito sugestivo de acometimento hipotalâmico-hipofisário por lesão infiltrativa. No entanto, o fato de o exame de imagem ter sido realizado em data posterior ao diagnóstico do DIC talvez justifique a ausência desse achado (8). Dentre as moléstias infiltrativas, citamos uma outra entidade, a hipofisite xantogranulomatosa, uma doença primária da hipófise que cursa freqüentemente com hipopituitarismo anterior, DIC, massa sólida ou cística na região hipofisária e achado histopatológico semelhante ao do caso descrito (9).

A deficiência da vasopressina varia em gravidade e, em humanos, é quase sempre causada pela destruição irreversível de mais de $80 \%$ dos neurônios magnocelulares hipotalâmicos produtores desse hormônio (10). O acometimento desses neurônios por doenças inflamatórias infiltrativas é descrito na sarcoidose, nas histiocitoses de células de Langerhans e nas histiocitoses de células não-Langerhans. Nesse último caso, especialmente no xantoma disseminado.

A histiocitose de células de Langerhans predomina na infância e é caracterizada por uma proliferação específica de células dendríticas ou de Langerhans pertencente ao sistema monocítico- macrofágico, com a capacidade de infiltrar diferentes sítios no organismo. Essas células são caracterizadas por apresentarem um citoplasma abundante com grânulos de Birbeck identificados à microscopia eletrônica. Em uma de suas

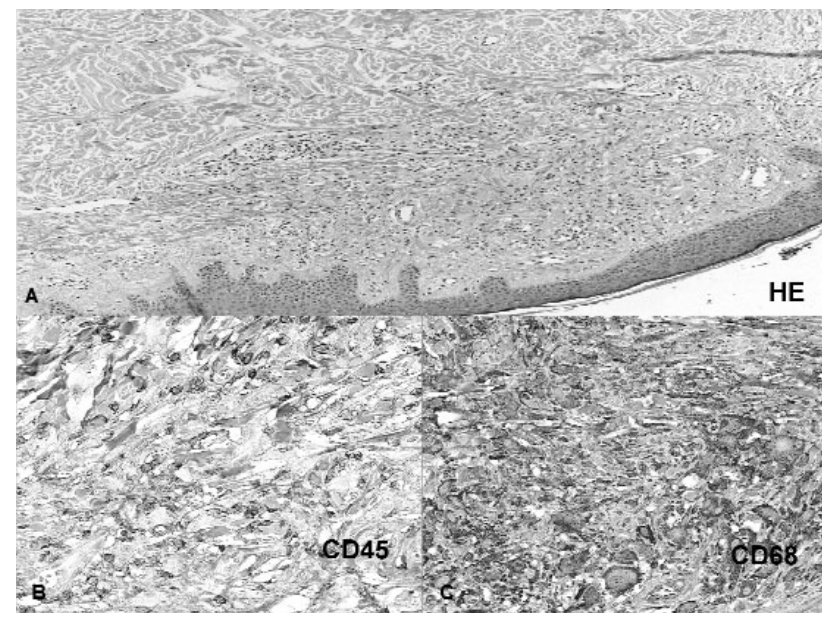

Figura 3. (A) Coloração de Hematoxilina-Eosina -50X. (B) Imuno-histoquímica positiva para antígeno CD45 (clone PD7/26 e 2B11). (C) Imuno-histoquímica com pesquisa do antígeno CD68 (clone KP1), fortemente positivo nas células da lesão. 
variantes, a doença de Hand-Schüller-Christian, o DIC encontra-se freqüentemente presente, associando-se a lesões osteolíticas e exoftalmia (3).

Já a histiocitose de células não-Langerhans é representada por uma série de doenças cutâneas caracterizadas por xantomatose cutânea localizada e não agressiva, com tendência à regressão espontânea, e ausência dos grânulos de Birbeck (2).

Os achados histológicos e imuno-histoquímicos obtidos pela biópsia da lesão cutânea deste paciente e a microscopia eletrônica mostraram resultados compatíveis com a histiocitose de células não-Langerhans, sugestivo de xantogranuloma juvenil. Como, no entanto, não existe achado histopatológico patognomônico de determinado tipo de histiocitose não-Langerhans, o diagnóstico exato destas entidades depende intimamente do quadro clínico (tabela 1).

Dentre as doenças do grupo das histiocitoses nãoLangerhans, somente o xantoma disseminado apresentase classicamente relacionado ao DIC, sendo que este último ocorre em aproximadamente $40 \%$ dos casos, com predileção por adolescentes e adultos jovens. Contudo, o xantoma disseminado manifesta-se, freqüentemente, por numerosas pápulas coalescentes em áreas de flexão cutânea $(11,12)$. Dois casos anteriormente descritos na literatura como exemplos da associação do xantoma disseminado ao DIC foram posteriormente questionados, pois, segundo a opinião de alguns autores, poderiam se tratar do xantoma papular, uma vez que não havia o infiltrado inflamatório e o quadro clínico característico do xantoma disseminado (2).

O xantogranuloma juvenil é a forma mais comum de histiocitose de células não-Langerhans (13). Acomete principalmente crianças no primeiro ano de vida, podendo, contudo, ocorrer em cerca de $15 \%$ dos casos em adultos $(2,13)$. O quadro clínico clássico é constituído por lesões cutâneas solitárias. Não obstante, é também descrito o encontro de lesões papulares múltiplas, definidas pela presença de mais de cinco lesões, predominando no tronco e cabeça, e que geralmente apresentam regressão espontânea $(14,15)$, assim como no nosso caso. Na literatura, encontramos apenas 16 casos de xantogranuloma em adulto (forma múltipla), com predomínio no sexo masculino e idade média de acometimento de 47 anos. O comprometimento sistêmico é raro mas, na forma cutânea múltipla, encontra-se presente em até $38 \%$ dos casos (14). Dentre os sítios de acometimento extracutâneo, os olhos são os mais afetados $(16,17)$, tendo sido esse excluído em nosso paciente pelo achado do exame oftalmológico normal.

A revisão da literatura mostra apenas uma criança de 10 anos com DIC associado ao xantogranuloma juvenil e múltiplas lesões cerebrais demonstradas por tomografia computadorizada (6). No paciente aqui relatado, a referida associação ocorreu em adulto jovem que apresentava, também, pansinusite. Dessa maneira, outras doenças xantomatosas, além do xantoma disseminado e da histiocitose de células de Langerhans, poderiam estar relacionadas ao DIC. O processo inflamatório difuso de seios paranasais pode também estar associado a essas doenças e já foi documentado em um paciente adulto com xantoma disseminado e DIC (18). Recentemente foi descrito um caso de DIC em uma criança com histiocitose cefálica benigna, uma outra variante da histiocitose nãoLangerhans (8).

Tabela 1. Diagnósticos diferenciais das doenças xantomatosas. [Modificada de Ferrando e cols. (4)]

\begin{tabular}{|c|c|c|c|c|}
\hline & XD & XGJ & $\mathbf{X P}$ & HCL (H-S-C) \\
\hline Idade & $\begin{array}{l}\text { adolescentes e } \\
\text { adultos jovens }\end{array}$ & $\begin{array}{l}\text { crianças, predominando } \\
\text { em menores que } 1 \text { ano }\end{array}$ & adultos & crianças \\
\hline Lesões cutâneas & $\begin{array}{l}\text { numerosas pápulas } \\
\text { castanho-amareladas, } \\
\text { confluentes nas dobras } \\
\text { de flexão }\end{array}$ & $\begin{array}{l}\text { pápula ou nódulo solitário } \\
\text { eritêmato-amarelado, } \\
\text { predominantes na cabeça, } \\
\text { pescoço e tronco }\end{array}$ & $\begin{array}{l}\text { pápulas ou nódulos } \\
\text { discretos com } \\
\text { distribuição generalizada }\end{array}$ & $\begin{array}{l}\text { pápulas ou nódulos } \\
\text { amarelados } \\
\text { disseminados ou } \\
\text { apenas no couro } \\
\text { cabeludo }\end{array}$ \\
\hline Lesões sistêmicas & $\begin{array}{l}\text { freqüentes: } \\
\text { SNC (DIC), sistema } \\
\text { respiratório superior }\end{array}$ & $\begin{array}{l}\text { raras: } \\
\text { olhos, pulmões, } \\
\text { fígado, SNC }\end{array}$ & não documentada & $\begin{array}{l}\text { freqüentes: } \\
\text { olhos, SNC (DIC), ossos }\end{array}$ \\
\hline Histopatologia & $\begin{array}{l}\text { células de Touton, } \\
\text { histiócitos, células } \\
\text { inflamatórias e espumosas }\end{array}$ & $\begin{array}{l}\text { células de Touton, } \\
\text { eosinófilos, neutrófilos, } \\
\text { histiócitos e } \\
\text { células espumosas }\end{array}$ & $\begin{array}{l}\text { células de Touton, } \\
\text { histiócitos e } \\
\text { células espumosas }\end{array}$ & $\begin{array}{l}\text { células dendríticas } \\
\text { de Langerhans, } \\
\text { células inflamatórias } \\
\text { e espumosas }\end{array}$ \\
\hline
\end{tabular}

XD, Xantoma Disseminatum; XGJ, Xantogranuloma Juvenil; XP, Xantoma Papular; HCL, Histiocitose de células de Langerhans; H-S-C, Síndrome de Hand-Schüller-Christian; SNC, sistema nervoso central; DIC, diabetes insipidus central. 
A dificuldade diagnóstica é mais uma particularidade das histiocitoses não-Langerhans, o que pode ser explicado pela hipótese de que essas representariam, na verdade, um espectro de doenças que, freqüentemente, se sobrepõem $(8,18)$.

Em suma, o relato deste caso acrescenta aos dados da literatura uma forma rara de apresentação clínica do DIC, em que a síndrome poliúrica se associa a manifestação cutânea xantomatosa discreta. Além disso, confirma a associação do DIC com as doenças histiocíticas de células não-Langerhans, de forma mais ampla do que a associação exclusiva com o xantoma disseminado. Por fim, os autores sugerem, a partir deste relato, a inclusão das outras formas de histiocitoses de células não-Langerhans entre as causas descritas de DIC, em especial o xantogranuloma juvenil, de maneira que se possa incluir um grupo maior de doenças com fisiopatologia semelhante e manifestações cutâneas que, muitas vezes, se confundem.

\section{REFERÊNCIAS}

1. Naves LA, Vilar LC, Augusto Cézar F, et al. Distúrbios na secreção e ação do hormônio antidiurético. Arq Bras Endocrinol Metab 2003;47:467-81.

2. Winkelmann RK. Cutaneous syndromes of non-X histiocytosis: a review of the macrophage-histiocyte diseases of the skin. Arch Dermatol 1981;117:667-72.

3. Kaltsas GA, Powles TB, Evanson J, Plowman PN, Drinkwater JE, Jenkins PJ, et al. Hypothalamo-pituitary abnormalites in adult patients with Langerhans cell histiocytosis: clinical, endocrinological and radiological features and response to treatment. J Clin Endocrinol Metab 2000;85:1370-7.

4. Ferrando J, Campo-Voegeli A, Soler-Carrillo J, Muñoz E, Solé M, Palou J, et al. Systemic xanthohistiocytoma: a variant of xantoma disseminatum? Br J Dermatol 1998;138:155-60.

5. Ringel E, Moschella S. Primary histiocytic dermatoses. Arch Dermatol 1985;121:1531-41.

6. Flach DB, Winkelmann RK. Juvenile xanthogranuloma with central nervous system lesions. J Am Acad Dermatol 1986;14:405-11.
7. Drummond JB, Martins JCT, Soares MMS, et al. Alterações da haste hipofisária e suas implicações clínicas. Arq Bras Endocrinol Metab 2003;47:458-66.

8. Weston WL, Travers SH, Mierau GW, Heasley D, Fitzpatrick J. Benign cephalic histiocytosis with diabetes insipidus. Pediatr Dermatol 2000;17:296-8.

9. Burt MG, Morey AL, Turner JJ, Pell M, Sheehy JP, Ho KKY. Xanthomatous pituitary lesions: a report of two cases and review of the literature. Pituitary 2003;6:161-8.

10. Robertson GL. Antidiuretic hormone. Normal and disordered function. Endocrinol Metab Clin North Am 2001;30:67194.

11. Altman J, Winkelmann RK, Rochester W. Xanthoma disseminatum. Arch Dermatol 1962;86:62-76.

12. Mishkel MA, Cackshott WP, Nazir DJ, Rosenthal D, Spaulding WP, Wynn-Williams A. Xanthoma disseminatum. Clinical, metabolic, pathologic, and radiologic aspects. Arch Dermatol 1977;113:1094-100.

13. Hernandez-Martin A, Boselga E, Drolet BA, Esterly NB. Juvenile xanthogranuloma. J Am Acad Dermatol 1997;36:35567.

14. Saad N, Skowron F, Dalle S, Forestier J, Balme B, Thomas L. Multiple adult xanthogranuloma: case report and literature review. Dermatology 2006;212:73-6.

15. Janssen D, Harms D. Juvenile xanthogranuloma in childhood and adolescence: a clinicopathologic study of 129 patients from the Kiel pediatric tumor registry. Am J Surg Pathol 2005;29:21-8.

16. Dehner LP. Juvenile xanthogranulomas in the first two decades of life: a clinicopathologic study of 174 cases with cutaneous and extracutaneous manifestations. Am J Surg Pathol 2003;27:579-93.

17. Imiela A, Carpentier O, Segard-Drouard M, Martin de Lassalle E, Piette F. Juvenile xanthogranuloma: a congenital giant form leading to a wide atrophic sequela. Pediatr Dermatol 2004;21:121-3.

18. Odell WD, Doggett RS. Xantoma disseminatum, a rare cause of diabetes insipidus. J Clin Endocrinol Metab 1993; $76: 777-80$.

Endereço para correspondência:

Antônio Ribeiro de Oliveira Jr.

Rua São Romão 343/701

30330-120 Belo Horizonte, MG 